\title{
Histomorphological spectrum of colonic biopsies: A two year study
}

\author{
Ch. Geetha ${ }^{1, *}$, M. Pavani' ${ }^{2}$, Shailaja Prabhala ${ }^{3}$, A.K. Deshpande ${ }^{4}$ \\ ${ }^{1,2}$ Assistant Professor, ${ }^{3}$ Professor, ${ }^{4}$ Professor and HOD, Dept. of Pathology, Kamineni Academy of Medical Sciences and \\ Research Centre, Hyderabad, Telangana, India
}

*Corresponding Author:

Email: drgeetha_nims@yahoo.com

Received: $17^{\text {th }}$ August, 2017

Accepted: $11^{\text {th }}$ November, 2017

\begin{abstract}
Introduction: Colonoscopy and accompanying mucosal biopsy is the diagnostic tool of choice in the evaluation of patients with colo rectal pathologies. The objectives of this study were to study the histo morphological spectrum of colonoscopic biopsies, to find age, gender, site distribution of these lesions and to correlate them with clinical presentation and colonoscopic diagnosis.

Materials and Methods: The study included all the colonoscopic biopsies received at Department of Pathology, Kamineni Academy of Medical Sciences and Research Centre, Hyderabad from January 2015 to December 2016, over a period of two years.

Results: There were 198 colonoscopic biopsies during this period. Two biopsies were inadequate for opinion and were excluded from the study. All the colorectal resection specimens, anal lesion were excluded from the study. Out of total 196 biopsies, 104 were non-neoplastic lesions, 92 were neoplastic lesions. Mean age of patients was 49.7 years with a male to female ratio of 1.6:1. Most common location of the lesion was rectum. The most common presenting complaint for both non-neoplastic and neoplastic lesions was bleeding per rectum. Non-specific colitis was commonest non-neoplastic lesion followed by ulcerative colitis. In the neoplastic lesions, adenocarcinoma was the commonest subtype followed by adenomatous polyps.

Conclusion: Both neoplastic and non-neoplastic lesions equally affect colon. Non-specific colitis, ulcerative colitis, Crohns disease, tuberculosis, amoebic colitis, eosinophilic enteritis, hamartomatous and hyperplastic polyps were the various non neoplastic lesions encountered in our study. Adenocarcinoma was the most common malignancy on colonic biopsies. Carcinomas occurred at a later age than adenomas. Colonscopic diagnosis correlated well with histopathology diagnosis in carcinomas.
\end{abstract}

Keywords: Colonoscopy, Mucosal biopsy, Non-neoplastic lesions, Neoplastic lesions, Rectum, Non-specific colitis, Adenocarcinoma.

\section{Introduction}

Colon is the seat of divergent lesions which include inflammatory, idiopathic, infectious and neoplastic diseases. Non specific colitis is the most common cause for colorectal pathology. Inflammatory bowel diseases (IBD) which include Crohns disease (CD) and Ulcerative colitis (UC) require specific and precise diagnosis for their proper management. Colonic tuberculosis (TB) may simulate CD clinically, endoscopically and histologically. Eosinophilic enteritis is a rare idiopathic disease characterized by eosinophil-predominant inflammation of $>50$ eosinophils/HPF in the colon.

Adenomatous polyps are premalignant lesions with varying degrees of dysplasia and can progress to carcinomas.

Colorectal cancer (CRC) is the third most common cancer in men $(663,000$ cases, $10.0 \%$ of the total cancers) and the second most common cancer in women $(570,000$ cases, $9.4 \%$ of the total cases) worldwide. ${ }^{1}$ Incidence rates for rectal cancer are higher than for other colon cancers in all parts of India. ${ }^{2}$ The absolute burden of CRC has also increased in India during last three decades with incidence of 4.3 and 3.4 for 100,000 population for males and females respectively. ${ }^{3}$
Colonoscopy along with accompanying mucosal biopsy is the most important tool in the workup/evaluation of patients with different neoplastic and non-neoplastic lesions of colon and rectum. ${ }^{4,5}$

Colonoscopy has been available since the early 1970 's. ${ }^{6,7}$ Colonoscopy is a safe procedure that allows direct visualization of the mucosa of the rectum, colon and terminal ileum. It is considered gold standard for screening colorectal carcinoma and can detect advanced colonic neoplasms in asymptomatic individuals. During the past decade, great emphasis has been placed on the use of colonoscopy for early detection and removal of adenomatous polyps to reduce incidence and mortality of colorectal carcinomas. ${ }^{8}$

Mucosal sampling through biopsy at the time of colonoscopic evaluation is crucial to the diagnosis and management of colorectal pathologies. Other therapeutic advantages of colonoscopy include hemostasis at the site of bleed, removal of polyp, stricture dilatation and decompression of obstructed bowel.

Mucosal biopsies are essential for confirming the colonoscopic diagnosis, to differentiate $\mathrm{CD}$ from UC and for differentiating IBD from other colitides, such as acute self-limited colitis. ${ }^{9}$ Mucosal biopsies have been shown to be the most accurate indicator of the pathological diagnosis, extent of involvement of the 
colon in IBD, which help in planning proper treatment strategies in affected patients. ${ }^{10}$

\section{Aim of the Study}

To study the spectrum of lesions in colon and rectum on colonoscopic biopsies, to find age, gender and site distribution of these lesions and to correlate them with presenting complaints and colonoscopic diagnosis.

\section{Materials and Methods}

The present study was a retrospective study of all the colonoscopic biopsies at Department of Pathology, Kamineni Academy of Medical Sciences and Research Centre, Hyderabad over a period of two years from January 2015 to December 2016. One hundred and ninety six biopsies from patients attending the Gastroenterology OPD were studied. Clinical details of lower gastrointestinal symptoms and colonoscopic findings were obtained wherever possible. All the biopsies were taken from the representative areas as per discretion of the gastroenterologist. Colonoscopic diagnosis when available was correlated with final histopathology diagnosis.

Inclusion Criteria: All the colonoscopic biopsies taken from colon, rectum, received in the Department of Pathology in the study period.

Exclusion Criteria: All the colorectal resection specimens, anal lesions were excluded. Also inadequate biopsies were excluded.

All colonoscopic biopsy specimens were collected in $10 \%$ neutral buffered formalin. They were processed and embedded with the mucosal surface being uppermost. Four micron thick serial sections were prepared and stained with hematoxylin and eosin $(\mathrm{H}$ and E). Detailed study of the sections was done under light microscope and diagnosis rendered accordingly. Alcian blue special stain was done in all the cases.

\section{Results}

A total of 198 colonoscopic biopsies were reviewed. Two cases showed inadequate material for definitive opinion and they were excluded from study.

The study included 121 males and 75 females with male to female ratio of 1.6:1. Biopsies were performed on patients of all age groups, the youngest being a four year old and oldest being a 90 year old male. Mean age of the patients was 50 years. Age distribution of lesions is summarised in Table 1.

Table 1: Age distribution of lesions

\begin{tabular}{|l|c|c|}
\hline S.No & Age (in years) & Number of cases (\%) \\
\hline 1 & $0-20$ & $10(5.1 \%)$ \\
\hline 2 & $21-30$ & $24(12.2 \%)$ \\
\hline
\end{tabular}

\begin{tabular}{|l|c|c|}
\hline 3 & $31-40$ & $24(12.2 \%)$ \\
\hline 4 & $41-50$ & $32(16.3 \%)$ \\
\hline 5 & $51-60$ & $48(24.4 \%)$ \\
\hline 6 & $61-70$ & $37(18.8 \%)$ \\
\hline 7 & $71-80$ & $16(8.1 \%)$ \\
\hline 8 & $81-90$ & $05(2.5 \%)$ \\
\hline \multicolumn{2}{|l|}{ Total } & $196(100 \%)$ \\
\hline
\end{tabular}

Most common location of the lesion was rectum (115 cases, $58.6 \%$ ). The other sites of biopsy included cecum (35 cases, 17.8\%), sigmoid (14 cases, $7.1 \%$ ), hepatic flexure (5 cases, $2.5 \%$ ), splenic flexure (5 cases, $2.5 \%$ ), descending colon (03 cases, $1.5 \%)$, ascending colon (01 case, $0.5 \%$ ), transverse colon (01 case, $0.5 \%$ ), ileo-ceacal valve (02 cases, $1.1 \%$ ). In the remaining 15 cases, $7.5 \%$ specific site in the colon was not mentioned.

Clinical details were available in 146 cases. Most common symptom was bleeding per rectum which was seen in 72 cases accounting for $49.3 \%$. Other clinical features included chronic diarrhoea (23 cases, $15.7 \%$ ), right iliac fossa pain (18 cases, 12.3\%), constipation (14 cases, $9.5 \%)$, obstruction (03 cases, 2\%), fever (05 cases, $3.4 \%)$, fissure in ano (02 cases, $1.3 \%)$ and anaemia (09 cases, 6.1\%).

The colonoscopic biopsies were divided as nonneoplastic and neoplastic as summarised in Table 2.

Table 2: Distribution of lesions

\begin{tabular}{|l|c|}
\hline Neoplastic & $92(46.5 \%)$ \\
\hline Non-neoplastic & $104(52.5 \%)$ \\
\hline Total & $196(100 \%)$ \\
\hline
\end{tabular}

Various histopathological diagnosis of non-neoplastic conditions are summarised in Table 3.

Table 3: Histopathological diagnosis of nonneoplastic lesions

\begin{tabular}{|l|c|c|}
\hline S.No. & Histopathology & No. of cases \\
\hline 1 & Non specific colitis & $50(49.1 \%)$ \\
\hline 2 & Ulcerative colitis & $23(22.1 \%)$ \\
\hline 3 & Crohns & $05(4.8 \%)$ \\
\hline 4 & TB & $07(06.6 \%)$ \\
\hline 5 & $\begin{array}{c}\text { Suppurative } \\
\text { Granulomatous }\end{array}$ & $01(0.9 \%)$ \\
\hline 6 & Amoebic colitis & $01(0.9 \%)$ \\
\hline 7 & Eosinophilic enteritis & $01(0.9 \%)$ \\
\hline 8 & $\begin{array}{c}\text { Inflammatory bowel } \\
\text { disease }\end{array}$ & $03(2.7 \%)$ \\
\hline 9 & $\begin{array}{c}\text { Solitary Rectal Ulcer } \\
\text { Syndrome (SRUS) }\end{array}$ & $01(0.9 \%)$ \\
\hline 10 & Hyperplastic polyp & $08(7.2 \%)$ \\
\hline 11 & $\begin{array}{c}\text { Juvenile/Hamartomato } \\
\text { us/Inflammatory polyp }\end{array}$ & $04(3.7 \%)$ \\
\hline \multicolumn{3}{|c|}{ Total } \\
\hline
\end{tabular}


Most common non-neoplastic lesion in the present study was non-specific colitis.

Inflammatory bowel diseases accounted for $27 \%$ of non-neoplastic lesions. Ulcerative colitis was more common than Crohns disease in colon. Mean age of presentation was 44.7 years. The male to female ratio was 2.5:1. Most common location was rectum (22 cases) and ceacum (3 cases). In the remaining three cases, specific site in the colon was not mentioned. In three cases, due to overlapping morphological features, specific categorisation was not done and it was reported as IBD. Most common symptom was chronic diarrhoea which was seen in sixteen cases, followed by bleeding per rectum seen in eight cases. Anal fissure and constipation was seen in other cases. All the cases showed good correlation with colonoscopic diagnosis.

Seven cases were diagnosed as Granulomatous inflammation of Koch's etiology (Fig. 1), one case was reported as suppurative granulomatous inflammation. Most common location in colon was cecum (5 cases), rectum ( 2 cases), splenic flexure ( 1 case). $\mathrm{M}: \mathrm{F}=1: 3$. Mean age was 34.7 years. Most common symptom was pain in abdomen.

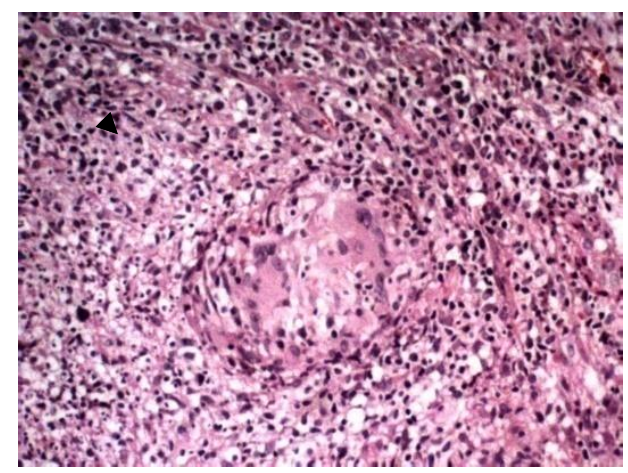

Fig 1: Granulomatous inflammation of Koch's etiology (H and E stain, 100x)

Hyperplastic polyps were reported in eight cases. Mean age was 47.5 years. Most common location was recto-sigmoid ( 5 cases) followed by cecum ( 3 cases). $\mathrm{M}: \mathrm{F}=3: 1$

Juvenile polyp was reported in a 4 year male in rectum.

Inflammatory polyps were reported in rectum.

Hamartomatous polyp was reported in 60 year male who presented with constipation.

Amoebic colitis was reported in two cases. Both were males with 50 years of age. Biopsy was done from ceacum in both the cases.

Eosinophilic colitis was reported in a 71year male who presented with pain in abdomen.

SRUS was reported in a 43 year male who presented with bleeding per rectum.

Microscopy of non-neoplastic lesions:

Non-specific colitis was characterized by neutrophilic/lymphoplasmacytic infiltrate in the lamina propria. No crypt abscess or decrease in goblet cells was observed.

Granulomatous inflammation was characterized by granulomas composed of epithelioid cell clusters and lymphoplasmacytic infiltrate in the lamina propria. Focal necrosis and occasional giant cells were noted.

Ulcerative colitis on microscopy showed distortion of mucosal lining, cryptitis, crypt abscesses, increase in number of neutrophils, lymphocytes and plasma cells in the lamina propria. Dysplasia was graded as mild, moderate and severe.

Crohn's colitis was characterized by small, multiple granulomas and lymphocytic infiltrate in the mucosa and submucosa.

It is important to differentiate tuberculosis (TB) from $\mathrm{CD}$, due to overlapping histo morphology. Caseous necrosis, acid-fast bacilli (which are present in a minority of biopsy specimens from patients with intestinal tuberculosis), larger size, more number and confluence of granulomas, presence of ulcers lined by bands of epithelioid histiocytes and disproportionate submucosal inflammation favour intestinal tuberculosis over Crohn's disease.

Amoebic colitis showed an inflammatory exudate with trophozoites of entamoeba revealing erythrophagocytosis.

Juvenile/inflammatory polyps showed a polypoid structure lined by columnar cells. The stroma showed dilated glandular structures filled with mucin and dense interstitial inflammation.

Hyperplastic polyps were detected, which showed superficial elongated crypts with upper parts of the crypts having luminal epithelial infoldings

SRUS showed surface ulceration, lamina propria revealed proliferation of fibroblastic and fibromuscular tissue with splaying of muscle fibres.

Histopathological diagnosis of various neoplastic lesions are summarised in Table 4.

Table 4: Histopathology of neoplastic lesions

\begin{tabular}{|l|l|c|}
\hline S.No & \multicolumn{1}{|c|}{ Histopathology } & $\begin{array}{c}\text { No. of cases } \\
(\%)\end{array}$ \\
\hline 1 & $\begin{array}{l}\text { Adenocarcinoma well } \\
\text { differentiated }\end{array}$ & $36(39.1 \%)$ \\
\hline 2 & $\begin{array}{l}\text { Adenocarcinoma } \\
\text { moderately differentiated }\end{array}$ & $15(16.3 \%)$ \\
\hline 3 & $\begin{array}{l}\text { Adenocarcinoma poorly } \\
\text { differentiated }\end{array}$ & $09(9.7 \%)$ \\
\hline 4 & $\begin{array}{l}\text { Adenocarcinoma } \\
\text { papillary type }\end{array}$ & $02(2.1 \%)$ \\
\hline 5 & $\begin{array}{l}\text { Adenocarcinoma } \\
\text { mucinous type }\end{array}$ & $02(2.1 \%)$ \\
\hline 6 & $\begin{array}{l}\text { Adenomatous polyp } \\
\text { tubular, villous, tubulo- } \\
\text { villous) }\end{array}$ & $26(28.2 \%)$ \\
\hline 7 & Melanoma & $01(1.1 \%)$ \\
\hline 8 & Schwannoma & $01(1.1 \%)$ \\
\hline
\end{tabular}




\begin{tabular}{|l|l|l|}
\hline & Total & $92(100 \%)$ \\
\hline
\end{tabular}

Adenomatous polyps accounted for $28.2 \%$ (26 cases) of all neoplastic lesions. They included tubular ( 2 cases), villous ( 4 cases) and tubulo villous adenomas (20 cases). Mean age at the time of presentation was 52.7years. There were 15 males and 11 females. There were 13 cases that showed varying degrees of mild to moderate to severe dysplasia. Malignant transformation was seen in three cases. Bleeding per rectum was the most common presentation.

Amongst 65 colonoscopic biopsies diagnosed as malignant lesions, 64 cases were adenocarcinomas accounting for $69.5 \%$ of all neoplastic cases and one case was malignant melanoma. Of the adenocarcinomas, 36 were of well differentiated, 15 were of moderately differentiated, 9 were poorly differentiated with 1 case revealing signet ring cell morphology (Figure 2), 2 cases each of mucin secreting carcinoma and papillary adenocarcinoma. Male: female ratio was 1.6:1. Mean age of presentation was 57 years. Majority of the cases were in the age group of 51-60 years.

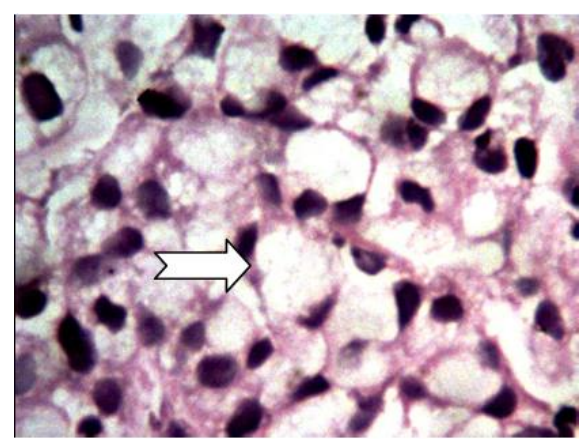

Fig. 2: Signet ring cell carcinoma $(\mathrm{H}$ and $\mathrm{E}, 400 \mathrm{X})$

Rectal melanoma was reported in a 66 year male who presented with constipation.

Rectal schwannoma was diagnosed in a 55 year old male.

Microscopic features of neoplastic lesions: Tubular adenomas showed tubular architecture with increased number of glands per unit area. Glands were crowded and lined by columnar epithelium. Villous adenomas were characterized by finger like or leaf like villous processes of lamina propria covered by dysplastic epithelium. Tubulo villous adenomas revealed features of both tubular and villous adenoma. Lining epithelium showed varying degrees of dysplasia from low grade to high grade.

Schwannoma showed a circumscribed lesion made up of fascicles of spindle cells.

Adenocarcinomas were characterized by irregular infiltrating glands lined by tall columnar cells with hyperchromatic nuclei, showing nuclear stratification and mitoses. They were graded as well differentiated, moderately differentiated and poorly differentiated based on the degree of differentiation. Papillary adenocarcinomas revealed a predominant papillary architecture of the tumor. Mucinous adenocarcinomas showed tumor cells floating in large extracellular mucin lakes which comprised at least $50 \%$ of tumor mass. Signet ring cell carcinomas showed tumor cells with signet ring morphology comprising $>50 \%$ of tumor cells with little glandular formation. Signet ring cells had abundant intracellular mucin, eccentrically pushed crescentic nucleus.

\section{Discussion}

Widespread use of flexible endoscopy has improved our understanding of the pathogenesis and evolution of disease processes, diagnosis and management of various colonic lesions. Colorectal lesions in the early stage produce very non-specific symptoms. Hence, colonoscopy is a very useful tool for screening and for the early detection of colonic lesions.

Mean age of the patients at the time of presentation was 50 years. These findings are similar to the observations of Phillipo et $\mathrm{al}^{11}$ and Karve et $\mathrm{al}^{7}$

In our study colonic adenomas were seen at a younger age (mean age 44years) than carcinomas (mean age 57 years)

In our study, the mean age of presentation in $\mathrm{TB}$ was 35years which is similar to the studies of Dutta et $\mathrm{al}^{12}$ and Leung VKS et al. ${ }^{13}$

Age distribution of all colonic lesions in comparision to other studies is summarised Table 5

Table 5: Age distribution of all colonic lesions in comparison to other studies

\begin{tabular}{|l|c|c|c|}
\hline Age (in years) & Abdulla et al ${ }^{[10]}$ & Karve et al $^{[7]}$ & Present study \\
\hline $0-10$ & $06(1.8 \%)$ & $04(2.5 \%)$ & $01(0.5 \%)$ \\
\hline $11-20$ & $28(8.4 \%)$ & $06(3.7 \%)$ & $09(4.5 \%)$ \\
\hline $21-30$ & $81(24.3 \%)$ & $29(18.2 \%)$ & $23(11.7 \%)$ \\
\hline $31-40$ & $77(23.1 \%)$ & $33(20.7 \%)$ & $24(12.2 \%)$ \\
\hline $41-50$ & $45(13.5 \%)$ & $24(15.1 \%)$ & $32(16.3 \%)$ \\
\hline $51-60$ & $65(19.5 \%)$ & $25(15.7 \%)$ & $48(24.5 \%)$ \\
\hline $61-70$ & $30(9.0 \%)$ & $05(3.1 \%)$ & $37(18.9 \%)$ \\
\hline $71-80$ & - & - & $16(8.2 \%)$ \\
\hline $81-90$ & - & - & $06(3.1 \%)$ \\
\hline
\end{tabular}




\begin{tabular}{|l|l|l|l|}
\hline Total & $332(100 \%)$ & $159(100 \%)$ & $196(100 \%)$ \\
\hline
\end{tabular}

In the present study, males were affected more than females and male: female ratios were 1.6: 1 in nonneoplastic lesions and 1.8: 1 in neoplastic lesions. The gender incidence of neoplastic lesions was in accordance with Das $\mathrm{P}$ et al..$^{15}$ Aljebreen AM et a ${ }^{16}$ and Abdulkareem FB et al ${ }^{17}$ which showed 2.5:1,1.3:1 and 1.3:1 respectively. Various studies on colorectal lesions attributed etiopathogenesis to westernized diet, tobacco and alcohol consumption which are more common in males. All the lesions are common in males than females except tuberculosis.

Majority of the neoplastic lesions were left sided, especially involving rectum followed by ceacum and sigmoid colon, similar to the findings made by Gurjeet et $\mathrm{al}^{18}$ and Shefali et al. ${ }^{7}$ Most common location for carcinomas was rectum similar to Mohandas et $\mathrm{al}^{3}$ Aljebreen $\mathrm{AM}$ et $\mathrm{al}^{16}$ and Das $\mathrm{P}$ et al. ${ }^{15}$ For Tuberculosis and Amoebic colitis, cecum is the most common site.

Rectal bleeding was the commonest presenting symptom for adenomas and malignant lesions in the present study which is in agreement with studies of Yawe KTet al ${ }^{19}$ and Saidi HS et al. ${ }^{20}$

Chronic diarrhoea is the most common symptom of IBD similar to the study of Pandey et al. ${ }^{21}$ These findings are in contrast to the findings of Badmapriya et $\mathrm{al}^{22}$ and Sood et $\mathrm{al}^{23}$ where bleeding per rectum was the most common symptom. Pain abdomen was the most common symptom in TB.

Non-neoplastic lesions (chronic nonspecific colitis, and sometimes acute colitis, acute on chronic colitis) accounted for $52.5 \%$ cases. Most common non neoplastic lesion was non specific colitis acconting for 53\% which correlates with the findings drawn by Deshpande $\mathrm{V}$ et $\mathrm{al}^{24}$ and Pandey et al. ${ }^{21}$ This might point to the importance of follow-up in such cases.

IBD is on the rise in India. It is a challenging disease with remissions and relapses which requires early diagnosis and prompt treatment. ${ }^{25,26}$ In India, UC was first reported in 1964 and CD was considered almost nonexistent till 1986. During the last 10 years, $\mathrm{CD}$ is being reported more frequently from different parts of India, especially southern India. ${ }^{27}$

Visual inspection of the colon and terminal ileum by colonoscopy along with biopsy plays an important role in workup/diagnosis and determining the disease activity in suspected IBD. They often establish the diagnosis and document the presence or absence of dysplasia. Periodic Surveillance of these patients helps in reducing the risk of colorectal cancer. ${ }^{10}$
Present study observed male preponderance in cases of ulcerative colitis similar to previous studies by Badmapriya et $\mathrm{al}^{22}$ and Sood et al. ${ }^{23}$ Disease prevalence was high in patients between 21 to 30 years and 41 to 50 years with diarrhoea as commonest presenting complaint. These findings contrasted observations of Badamapriya et al and Sood et al where bleeding per rectum was commonest symptom. ${ }^{22,23}$

TB is endemic in India. Differentiating CD from TB requires correlation of clinical features, endoscopy, histology, radiology and treatment response. About 35$45 \%$ of patients with $\mathrm{CD}$ in India are initially diagnosed to have TB. ${ }^{12}$ In our study, 7 cases of TB, 5 cases of CD were reported. Common site affected was cecum in both $\mathrm{TB}$ and $\mathrm{CD}$. Colonoscopy studies show that $\mathrm{CD}$ patients usually have longitudinal ulcers, cobblestone appearance of mucosa and anorectal involvement. ${ }^{12}$ Presence of AFB on histology was present only in one of our cases.

In the present study, neoplastic lesions accounted for 92 cases, of which benign lesions were 27 (29.3\%) and malignant lesions were 65 (70.7\%). This correlated with study done by Teague et $\mathrm{al}^{28}$ in which benign lesions accounted for $26.3 \%$ and malignant lesions were $29.8 \%$.

In our study, neoplastic lesions of colon commonly ocurred in between 40 to 60 years of age. This was in accordance with studies done by Aljebreen AM et al. ${ }^{16}$ Shen SS et $a l^{5}$ Das $P$ et al ${ }^{15}$ and Abdulkareem FB et al ${ }^{17}$ but the mean age of presentation varied in these studies.

Mean age of presentation in adenomas was less than carcinomas in our study. Malignant tumors have a long natural history and present at a later age explaining adenoma-carcinoma sequence. Adenomas, if identified and are resected early help in prevention of carcinomas.

Most common type of carcinoma was adenocarcinoma. Mean age of presentation was 57 years. Majority of the cases fall in the age group of 5160 years. Male: Female ratio is 1.6:1 Of the adenocarcinomas, 36 cases $(56.2 \%)$ were well differentiated, 15 cases $(23.4 \%)$ were moderately differentiated, 9 cases $(14 \%)$ were poorly differentiated with 1 case $(1.5 \%)$ revealing signet ring morphology, 2 cases $(3.1 \%)$ each of mucin secreting carcinoma and papillary adenocarcinoma. These findings are similar to the observations of Phillipo et al. ${ }^{11}$ All these findings are in accordance with the study series of Laishram RS et al. ${ }^{29}$ Distribution of adenocarcinomas in comparision to other studies is summarised in Table 6 .

Table 6: Distribution of adenocarcinomas in comparision to other studies

\begin{tabular}{|l|c|c|c|c|}
\hline & $\begin{array}{c}\text { Laishram RS et } \\
\mathbf{a l}^{[29]}\end{array}$ & $\begin{array}{c}\text { Shyamal Kumar et } \\
\mathbf{a l}^{[30]}\end{array}$ & $\begin{array}{c}\text { Karve et al } \\
{\left[{ }^{[3]}\right.}\end{array}$ & Present study \\
\hline $\begin{array}{l}\text { Total number of } \\
\text { cases }\end{array}$ & $54(100 \%)$ & $180(100 \%)$ & $68(100 \%)$ & $64(100 \%)$ \\
\hline
\end{tabular}

Indian Journal of Pathology and Oncology, April-June, 2018;5(2):242-248 


\begin{tabular}{|l|c|c|c|c|}
\hline Well differentiated & $17(31.4 \%)$ & $51(28.3 \%)$ & $24(35.2 \%)$ & $36(56.2 \%)$ \\
\hline $\begin{array}{l}\text { Moderately } \\
\text { differentiated }\end{array}$ & $20(37 \%)$ & $49(27.2 \%)$ & $25(36.7 \%)$ & $15(23.4 \%)$ \\
\hline Poorly differentiated & $17(31.4 \%)$ & $20(11.1 \%)$ & $9(13.2 \%)$ & $8(12.5 \%)$ \\
\hline Mucinous type & - & $32(17.7 \%)$ & $8(11.7 \%)$ & $2(3.1 \%)$ \\
\hline Signet ring cell type & - & $28(15.5 \%)$ & $2(2.9 \%)$ & $1(1.5 \%)$ \\
\hline Papillary type & - & - & - & $2(3.1 \%)$ \\
\hline
\end{tabular}

\section{Conclusion}

The histomorphological spectrum of colorectal biopsies encompasses various conditions ranging from non-specific/infectious conditions, inflammatory disorders and precancerous lesions to colorectal malignancies. Colonic lesions are more common in males. The rectum is most commonly affected by adenomas and carcinomas, whereas, the cecum is commonly affected by TB and CD. Non-neoplastic lesions are more common than neoplastic lesions. Non specific colitis is the most common lesion. Clinical, colonoscopic and histopathological correlation is essential to distinguish between TB and Crohns disease. Adenomas occur at an earlier age than carcinomas. Most common carcinoma is adenocarcinoma. Screening for colorectal cancer by colonoscopy with removal of precancerous lesions is a powerful and effective approach for reducing colorectal cancer incidence and mortality.

\section{References}

1. Ferlay J, Freddie B, Forman D, Mathers C, Parkin DM. Estimates of worldwide burden of cancer in 2008: Globocan 2008. Int J Cancer. 2010;127:2893-917.

2. Curado MP, Edwards B, Shin HR, Storm H, Ferlay J, Heanue M, et al. Cancer Incidence in Five Continents, Volume IX. IARC Scientific Publication, No 160 IARC, Lyon 2007.

3. Mohandas. Colorectal cancer in India: controversies, enigmas and primary prevention: Indian J Gastroenterol. 2011; 30(1):3-6.

4. Qayyum A, Sawan AS. Profile of colonic biopsies in King Abdul Aziz University Hospital, Jeddah. J Park Med Assoc 2009; 59(9):608-11.

5. Cherneck and Berger. In: laboratory test and diagnostic procedure. $5^{\text {th }}$ edn; 2008:65-66.

6. Ignjatovic A, Saunders BP. Non-polypoid colorectal neoplasms are relatively common worldwide. Gastrointest Endosc Clin N Am. 2010; 20(3):417-29.

7. Karve SH, Vidya K, Shivarudrappa AS, Prakash CJ. The Spectrum of colonic lesions: A Clinico-pathological study of colonic biopsies. Indian Journal of Pathology and Oncology 2015; 2(4):189-209.

8. Siddique I, Mohan K, Hasan F, Memon A, Patty I, AlNakib B. Appropriateness of indication and diagnostic yield of colonoscopy : First report based on the 2000 guidelines of the American Society for Gastrointestinal Endoscopy. World J Gastroenterol 2005; 11(44):7007-13.

9. Chutkan RK, Waye JD.Endoscopy in Inflammatory bowel disease. In: Kirsner JB, ed. Inflammatory bowel disease.5th ed. Baltimare: Williams and Wilkins: 2000: 453-777.
10. Greene FL, Livstone EM, Troncale FJ. The role of fibre optic colonoscopy in the diagnosis of colonic and rectal diseases. Comm Med.1973; 37:439-42.

11. Phillipo LC, Mabulla DM, Joseph BM, Rambau PF, Jaka $\mathrm{H}$, Koy $\mathrm{M}$ et al. Clinicopathological patterns and challenges of management of colorectal cancer in a resource-limited setting: a Tanzanian experience. World Journal of Surgical Oncology 2013;11:88-95.

12. Dutta AK, Sahu MK, Gangadharan SK, Chacko A. Distinguishing Crohn's disease from intestinal tuberculosis - a prospective study. Tropical Gastroenterology 2011;32 (3):204-209.

13. Leung VKS, Law ST, Lam CW, Luk ISC, Chau TN, Loke TKL et al. Intestinal tuberculosis in a regional hospital in Hong Kong: a 10 year experience. Hong Kong Med J 2006;12:264-71.

14. Hassan Abdulla Al-aquili. Clinical, colonoscopic and histopathological evaluation of lower gastrointestinal bleeding. Kufa Med, Journal 2012;15:30-39.

15. Das P, Vaiphei K, Jain D, Wig JD.p53 and mdm2 expression in colorectal carcinoma:a correlative analysis with clinical staging and histological parameters. International journal of surgical pathology 2007;15 (4):335-45.

16. Aljebreen AM. Clinico-pathological patterns of colorectal cancer in Saudi Arabia: younger with an advanced stage presentation. Saudi Journal of Gastroenterology 2007;13(2):84.

17. Abdulkareem FB, Abudu EK, Awolola NA, Elesha SO, Rotimi O, Akinde OR, AnunobiCC. Colorectal carcinoma in Lagos and Sagamu, Southwest Nigeria: a Histopathological review. World J Gastroenterol 2008;14(42):6531-35.

18. Gurjeet K, Abdelhafid M, Raihanc N, Radzid M, Khamizar We, Lee Suk Kam. Mismatch repair genes expression defects \& association with clinicopathological characteristics in colorectal carcinoma. Indian J Med Res 2011;134(2):186-192.

19. Yawe KT, Bakeri AA, Pindiga UH. Clinicopathological pattern and challenges in the management of colorectal cancer in sub-saharan Africa. J Chinese Clin Med 2007;2:688-95.

20. Saidi HS, Karuri D, Nyaim EO: Correlation of clinical data, anatomical site and discuss stage in colorectal cancer. East Afr Med J 2008;85:259-62.

21. Megha SP, Ashish P, Dombale VD. Histomorphological Profile of Colonoscopic Biopsies - A Two Year Study in a Tertiary Care Hospital in South India. International Journal of Science and Research (IJSR). ISSN (Online): 2319-7064.

22. Badmapriya D, Kumar VS. Profile of Ulcerative colitis in South India Region: Karaikal. IJPBS 2011;1(2):47-51.

23. Sood A, Vandana M, Sood N, Puri S, Kaushal V. Profile of Ulcerative Colitis in a North India Hospital. Journal of Indian Academy of Clinical Medicine 1998;5(2):124-128.

24. Deshpande V, Hsu M, Kumarasinghe MP, Lauwers GY. The clinical significance of incidental chronic colitis: a study of 17 cases. Am J SurgPathol 2010; 34(4):463-9. 
25. Podolsky DK. Inflammatory bowel disease. NEJM 1991;325:928-37.

26. Satsangi J, Silverberg MS, Vermaire $S$ et al. The Montreal classification of inflammatory bowel disease: Controversies, consensus, and implications. Gut 2006;55:749-53.

27. Gunisetty S, Tiwari SK, Bardia A, Phanibhushan M, Satti $\mathrm{V}$, Habeeb MA et al. The epidemiology and prevalence of Ulcerative colitis in the South of India. Open Journal of Immunology 2012;2:144-48.

28. Teague RH, SalmonPR, Read AE. Fibreoptic examination of the colon: a Review of 255 cases. Gut 1973;14(2):139.

29. Laishram RS, Kaiho N, Shimray R, Devi SB, Punyabati $\mathrm{P}$, Sharma DC. Histopathological evaluation of Colorectal Carcinomas status in Manipur, India. International Journal of Pathology, 2010;8(1):5-8.

30. Halder SK. Epidemiological, Clinico-Pathological Profile and Management of Colorectal Carcinoma in a Tertiary Referral Center of Eastern India. JKIMSU, 2013;2(1):4550 . 